NBER WORKING PAPER SERIES

\title{
AGENTS OF EMBEDDEDNESS
}

\author{
Pierre Azoulay \\ Working Paper 10142 \\ http://www.nber.org/papers/w10142 \\ NATIONAL BUREAU OF ECONOMIC RESEARCH \\ 1050 Massachusetts Avenue \\ Cambridge, MA 02138 \\ December 2003
}

Rebecca Henderson played an essential role in sharpening the main argument. For useful comments, I thank Heather Haveman, Ray Horton, Paul Ingram, Ozgecan Kocak, Toby Stuart, and Sid Winter. I am grateful to Mark Hovde and FastTrack, Inc. for providing the data, and to John Vogel for his help in setting up the site visits. Financial support from the Center for Innovation and Product Development and the Industrial Performance Center at MIT is gratefully acknowledged. The usual disclaimer applies. The views expressed herein are those of the authors and not necessarily those of the National Bureau of Economic Research.

(C2003 by Pierre Azoulay. All rights reserved. Short sections of text, not to exceed two paragraphs, may be quoted without explicit permission provided that full credit, including $\mathbb{C}$ notice, is given to the source. 
Agents of Embeddedness

Pierre Azoulay

NBER Working Paper No. 10142

December 2003

JEL No. J410, L220, L650, O320

\begin{abstract}
$\underline{\text { ABSTRACT }}$
A rich literature argues that interorganizational networks foster learning and coordinated adaptation among their constituents, but embedded ties between organizations are not ubiquitous. What explains this heterogeneity? Acknowledging the influence of agency relationships within organizations can help refine the scope of embeddedness arguments. This idea is explored in an indepth qualitative examination of sourcing practices in drug development. The outsourcing of central laboratory services is characterized by repeated interactions, relationship-specific investments, and fine-grained information transfer between buyers and suppliers. In contrast, embedded relationships with contract research organizations have failed to materialize, despite the repeated efforts of exchange partners. Drawing on fieldwork conducted at six pharmaceutical and biotechnology firms, I explain why outsourcing deals take the form of embedded relationships in the first setting, and of seemingly inefficient spot contracts in the second setting. The evidence suggests that the structure of constituent firms' internal labor markets powerfully shapes and constrains the scope of interorganizational networks.
\end{abstract}

Pierre Azoulay

Columbia University

Graduate School of Business

3022 Broadway

704 Uris Hall

New York, NY 10027-6902

and NBER

pa2009@columbia.edu 


\section{Introduction}

Over the past decade, sociologists have drawn attention to network forms of organization, including alliances, joint-ventures, and long-term supply relationships (Granovetter, 1985; Powell, 1990; Podolny and Page, 1998). Work in this tradition has produced fascinating ethnographic evidence, which, at first glance, presents a puzzle for the purported economic efficiency of markets (Uzzi, 1997). Common themes in this stream of research include the assertion that structures between organizations do not lay neatly on a markethierarchy continuum, but operate in a distinct embedded logic of exchange (Uzzi, 1996); that networks are shaped by the extant social structure (Gulati and Gargiulo, 1999); and that, although they expose participating firms to hold-ups, networks promote firm performance through interfirm resource pooling, cooperation and coordinated adaptation (Powell et al., 1996; Dyer and Singh, 1998; Helper et al., 1999).

While this literature has undoubtedly enriched our understanding of firms and other economic institutions, the scope of embeddedness arguments is ill-defined: if relational governance enhances organizational performance, why are arms-length relationships between firms so prevalent? In this paper, I contend that firms' internal organizational arrangements may forestall the emergence of embedded relationships between firms, even when exchange partners perceive that adopting relational modes of governance would yield substantial ben-

efits. The argument brings together the interorganizational networks literature with a much older sociological tradition dealing with issues of trust and cooperation inside organizations (Gouldner, 1954; Blau, 1955; Dalton, 1959).

Two activities often outsourced by pharmaceutical firms - the coordination of clinical trials and the provision of laboratory services - provide the paper's empirical backdrop. Since the mid-1980s, Contract Research Organizations (CROs) have partly replaced the in-house labor force necessary to coordinate and monitor clinical trials. Because the data-production activities performed by $\mathrm{CRO}$ employees are highly interdependent with the knowledge-production activities conducted by employees of pharmaceutical firms, clinical development outsourcing is precisely the type of setting where one would expect embedded 
ties to be beneficial. However, embedded buyer-supplier relationships have not materialized, despite the repeated efforts of both upstream and downstream firms. In contrast, relational governance prevails in the outsourcing of central laboratory services. Relationships between pharmaceutical firms and central laboratories (which analyze and perform tests of patients' blood or tissue samples, an important intermediate input into the clinical trials process) are characterized by repeated interactions, relationship-specific investments, and fine-grained information transfer. Using this second setting to rule out a number of alternative explanations, I set out to explain the reasons behind the failure of embeddedness in the first setting. The empirical exercise relies on ethnographic fieldwork conducted at six pharmaceutical firms, supplemented by telephone interviews with personnel of ten different suppliers.

The evidence suggests that the presence of embedded ties between firms is influenced by the nature of labor market institutions within firms. Whereas central lab employees are highly trained, organized in self-directed workteams, and have relatively long tenure, CROs pay low wages, invest minimally in training, and attract inexperienced staff prone to "job hopping." It is also possible to compare CRO staff with pharmaceutical company employees performing exactly the same activity, since pharmaceutical firms rely simultaneously on insiders and outsiders to coordinate and monitor clinical trials. There again, suppliers run "data-production sweatshops" that stand in sharp contrast with buyers' "posthierarchical" organizations and their attendant set of human resource practices (Zuboff, 1988; Osterman, 1994). CROs' Taylorist approach to the organization of work undermines the embedding process because of its exclusive reliance on "hard" measures of performance, its fostering of job designs inimical to teamwork, and the hierarchical constraints it puts on information flows. In turn, arms-length contracting between firms raises suppliers' returns to structuring the employment relationship along Taylorist lines. This vicious circle results from a selffulfilling failure of expectations. Breaking this vicious circle is especially difficult in clinical development, as seemingly inefficient spot contracts with CROs buffer pharmaceutical firms' employees against the large shocks that often affect the drug development pipeline.

Consistent with previous research (Axelrod, 1984; Heide and Miner, 1992; Baker et al., 2002; MacMillan and Woodruff, 1999), I also find that the expected length of the relation- 
ship influences the formation of embedded ties. Anticipating that a relationship may be terminated in the future through no fault of its own, a supplier will hesitate to make specific investments - for example by dedicating teams to a particular client. Since the demand for clinical monitoring services tends to be lumpier and more unpredictable than the demand for laboratory services, the "shadow of the future" looms smaller in the first setting than in the second, thus providing an additional reason for the dearth of "hand-in-glove" supply relationships between pharmaceutical firms and CROs. While intuitively appealing, this explanation is not entirely compelling; in principle, interorganizational cooperation could be maintained if information about exchange partners was monitored with enough accuracy and sanctions administered by the "community" of pharmaceutical firms through a multilateral reputation mechanism (Raub and Weesie, 1990; Kandori, 1992). Institutions that facilitate the informal sharing of information about suppliers do exist in the pharmaceutical industry. Yet, embedded ties fail to emerge because the usefulness of this information is contingent on CROs' rate of employee turnover. In keeping with the paper's overall argument, the shadow cast by the expectation of future interactions on the strength of interorganizational ties depends on the structure of internal labor markets.

\section{Agents, Agency, and Embeddedness}

The past decade has seen remarkable advances in social scientists' understanding of network forms of organizations, loosely defined as "any collection of actors that pursue repeated, enduring exchange relations with one another and, at the same time, lack a legitimate organizational authority to arbitrate and resolve disputes that may arise during the exchange" (Podolny and Page, 1998, p. 59). Organizational sociologists have both documented the prevalence of such arrangements and marshaled an impressive amount of evidence pointing to the superiority of such "embedded" modes of exchange over the anonymous market transactions that are the staple of textbook economic theory. This line of inquiry also has been successful in buttressing the claim that networks do not constitute hybrids between the polar organizational forms of markets and hierarchies (Williamson, 1985 and 1996), but 
define a distinct logic of exchange (Powell, 1987). In particular, the simultaneous use of price, authority and trust as control mechanisms appears to be relatively frequent in ongoing interorganizational exchanges - even in settings characterized by high transactions costs (Bradach and Eccles, 1989; Stinchcombe, 1990).

One overarching weakness of this literature is that its theoretical scope is ill-defined. As acknowledged by Podolny and Page in their review, we may have a good understanding of why economic actors might want to structure exchange in networks, but we have less understanding of why they often fail to do so. Yet, a theory of the network form needs a reliable answer to the question "why aren't all interfirm exchanges structured as relational contracts?" just like transaction costs economics, as part of its theoretical apparatus, needs to reckon with the question "why don't all exchanges take place in a single firm?"

One might argue that framing the question above as a puzzle betrays a functional mode of reasoning according to which institutions originate in order to solve economic problems (Granovetter, 1992). As past research has pointed out, it may be hazardous to presume that embeddedness can be engineered, since the social ties that constitute its very fabric require affect and empathy, qualities that cannot be summoned at will (Ingram and Roberts, 2000). This objection, reasonable as it may be, cannot provide a complete explanation for the institutional heterogeneity that even the most casual form of observation makes plain. In the automobile industry, for instance, the Japanese system of interorganizational relations was successfully transplanted to US plants owned by Japanese manufacturers, despite the legacy of traditional Fordist organizational practices prevalent in the "transplant corridor" of the lower Midwest and upper South (Florida and Kenney, 1991). Subsequently, this system was gradually adopted by domestic American firms (Helper and Sako, 1995). In particular, Chrysler appears to have been able to emulate - albeit with a long lag — "cooperative" supplier-management practices, despite a previous history of contentious relationships (Dyer, 1996).

I propose a distinct explanation that acknowledges the role of agents within the organizations constituting the network, along with the influence of the agency relationships to which 
they are part. Organization theory has only recently begun to grapple with the mechanisms through which individual-level action affects interorganization-level outcomes (Zaheer et al., 1998). In part, this reflects that much empirical research on interorganizational networks has focused on entrepreneurial firms, a setting in which representing a participant firm as a unitary node within a network does not result in the loss of crucial information. ${ }^{1}$ A methodological bias might also be at play: conflating a firm's hierarchy into a node on a network map enables the application of traditional sociometric analysis to the study of interorganizational networks (e.g., Gulati and Gargiulo, 1999).

Recognizing that it is individuals as members of organizations who trust — rather than organizations themselves - has led scholars to take the natural first step of focusing on the role of "boundary spanners" in creating, maintaining, and dissolving interorganizational ties. For example, professional transitions for these individuals is often associated with a higher hazard of dissolution for the ties they helped broker (Baker et al., 1998; Broschak, 2002). But this evidence comes from the advertising industry, a setting in which business relationships tend to be highly personalized. In a more typical industrial setting, this study focuses less on the influence of individual agents than on the type of employment relationships prevailing inside the firms to which they belong.

To lay out the argument, I use the following rhetorical device. I focus on a sector of the economy - clinical development in the pharmaceutical industry — in which exchange characteristics appear at first glance indistinguishable from other settings in which embedded supply relationships have emerged and performed well. I show that such relationships have nonetheless failed to materialize, despite repeated efforts of both buyers and suppliers. I set out on a qualitative exploration of the root cause behind this failure. The analysis is made more persuasive by the comparison with a closely-related activity — central laboratory services - which shares many characteristics of clinical development but also differs from it in a few important (and relevant) respects.

\footnotetext{
${ }^{1}$ For example, Uzzi (1997: 38) argues that an advantage of studying garment firms is that CEOs "are involved in all key aspects of the business and consequently have first-hand knowledge of the firm's strategy and administrative activities."
} 


\section{Data and Methods}

I conducted field and ethnographic analysis at six pharmaceutical and biotechnology firms in the United States, focusing exclusively on two important activities performed in the course of drug development: the coordination of clinical trials, and the processing and analysis of patient samples in central laboratories. The choice of setting was prompted by a discussion with two ex-CRO employees who had described vividly the contrast between human resource practices prevailing at their former employer with those prevailing in their current job. Data collection followed grounded theory building techniques (Glaser and Strauss, 1967), although the analysis is not framed as an exercise in hypothesis testing. Rather, it aims to re-interpret existing theory by drawing attention to important tendencies that have previously been ignored (Vallas, 2003).

The market for clinical development exhibits a two-mode structure, with clear role differentiation between buyers (pharmaceutical sponsors of clinical trials) and suppliers (CROs and central labs). Therefore, I complemented the field study with telephone interviews with personnel of ten suppliers (seven CROs and three central labs) so as to avoid providing a one-sided account. The selection of cases followed theoretical sampling (Eisenhardt, 1989). As is often the case in field research, I was constrained by the need to gain access, a timeconsuming process requiring the negotiation of confidentiality agreements with each research site. Nonetheless, as is displayed in Table 1, the set of firms studied is quite diverse in terms of geographic dispersion, size, age, and breadth of product portfolio. Similarly, both small and large firms were included in the sample of suppliers.

While in the field, I was attentive to the need of interviewing staff at various levels of responsibilities and "hands-on interaction" with CROs and central laboratories. I systematically interviewed the Vice President for Clinical Research (except in one firm) as well as employees in charge of negotiating outsourcing contracts, but I also insisted on talking at length with project managers, clinical data managers, and clinical monitors involved on a daily basis in projects contracted out to $\mathrm{CROs}^{2}$ In the course of performing telephone

\footnotetext{
${ }^{2}$ Throughout the paper, the terms clinical study, clinical trial, and project are synonymous.
} 
interviews with suppliers, the point of contact was the business development manager, but for the three largest suppliers, I also interviewed a project manager, the human resource manager, and one to two employees from the rank and file.

I made initial contact with outsourcing managers using a variety of channels: an industry conference, an independent consultant, and two dissertation advisers' industry contacts. I introduced myself as a doctoral student writing his dissertation on the outsourcing practices of pharmaceutical firms in drug development. In-depth interviews were open-ended, lasting from a half-hour to three hours, with one hour being the norm. In five of the six firms, I spent three days on-site interviewing personnel, and in one firm, I was privy to a projectteam meeting. These trips enabled me to gather first-hand ethnographic data on humanresource practices and the nature of buyer-supplier relationships. After asking permission from subjects, I recorded each interview using a pocket-size tape recorder. The recordings were transcribed within a few days after each site visit so as to maximize accuracy. Field observations and anecdotes were separately jotted down in a spiral notebook.

The study proceeded in five stages. Stage one involved open-ended, moderately directive interviews. I conducted interviews carefully so that natural alternative interpretations of the facts could be examined, probing, for example, the existence of social ties between buyers' and suppliers' employees. I used nondirective items to probe sensitive issues, for example "Do you have further examples of this?" or "Can you give me a more detailed description of what happened?" When respondents expressed strong negative feelings about their suppliers (a fairly common occurrence), I usually pressed them by asking why they thought these suppliers were used at all. The Appendix lists the interview items.

In the second stage, I began to organize the data according to a crude and preliminary working framework. A "cross-site display," shown in Table 2, indicates the frequency and weighting of data across cases (Miles and Huberman, 1994). Armed with this understanding of buyers' perspective, I then proceeded to interview suppliers on the phone in stage three. Since one of my objectives was to compare and contrast buyers' and suppliers' perceptions 
regarding the nature of their relationships, I was careful not to lead the interview with the insights I had gained in stage two.

In the fourth stage, the analysis of the evidence proceeded by iteration. A given narrative suggested a model that, when explicated, had implications for the structure of relationships within which the events occurred. Those implications forced me to reconsider the narrative and then to reevaluate the extent to which key elements of the narrative lay outside the proposed theory. This inductive approach challenged both the evidence about the event of interest and theories that structured that evidence (Bates et al., 2000).

The fifth and final stage focused on gaining construct and external validity. This was achieved in two ways. First, I conferred with five managers from companies who did not participate in the study at the leading industry conference. Tellingly, none of these managers told me that he or she had learned anything new from the study. Instead, they said I had presented in a more systematic form inchoate ideas they held about the structure of supply relationships in their industry. I take this as evidence that what follows is not a mere artifact of the selection of firms. Second, I triangulated the qualitative finding of the absence of embedded ties with CROs using data from FastTrack, Inc. Since 1991, this company has gathered clinical development information from subscribing pharmaceutical companies in order to help them better. As a result, I believe the chance of response bias is low, given the sample's breadth and the cross-checking of interview and archival data.

\section{Engineering Embeddedness: Successes and Failures}

I begin by describing the two research settings in some detail. In doing so, I establish a number of facts upon which the theory-building exercise is grounded. First, both the coordination of clinical trials and central lab services appear to constitute auspicious settings for the development of embedded ties between buyers and suppliers, in light of extant theory. Second, in both cases buyers and suppliers attempted to develop such ties. Third, only in the latter setting were they successful in doing so. 
In order to gain regulatory approval for market introduction, the Food and Drug Administration (FDA) requires that a pharmaceutical company provide substantial evidence of a drug's effectiveness through adequate and well-controlled clinical investigations. Although the details of these requirements have evolved over the years, proof of effectiveness must be provided by the results of randomized control trials. Running these trials effectively and documenting them to the satisfaction of the FDA is an enormously complex and costly task (Mathieu, 1997; Spilker, 1991). I focus here on two of the activities that are central to success: the coordination of clinical trials and the processing and analysis of patient samples in central laboratories. Such a narrow focus is important since comparisons between types of supply relationships are usually confounded by task heterogeneity. Controlling for this kind of environmental variation appears necessary to draw inferences from qualitative data.

Until the mid-1980s, firms relied on an in-house labor force of clinical monitors to recruit, coordinate, and supervise the large number of investigators needed to conduct experimental human studies. Proper monitoring of clinical investigations is an integral part of a set of rules known as "Good Clinical Practices" that are mandated and enforced by regulatory authorities. While monitoring and clinical data management are unglamorous tasks, they are critical to the extent that skimping on data quality may jeopardize the scientific credibility of a new drug application and, more importantly, damage the reputation of the sponsor with regulatory agencies.

Since the mid-1980s, these duties have been outsourced to a new breed of specialized subcontractors called Contract Research Organizations (CROs), but vertical disintegration rarely applies to the totality of a firm's portfolio of projects (Azoulay, 2003b). As a result, the coordination and monitoring of clinical trials provides an example of the "plural form" (Bradach and Eccles, 1989), whereby distinct organizational control mechanisms are operated simultaneously for the same function by the same firm. Over time, CROs have extended the range of services they provide to include protocol design, biostatistical analysis, and report writing. The contract research industry was until recently growing at the brisk pace of $20 \%$ per year, and it is estimated that up to one fifth of overall pharmaceutical development 
budgets are captured by these independent firms, representing slightly less than $\$ 7$ billion in 2001 (Mathieu, 2003).

Sociologists have long noted that organizations must perform their technical work internally and present an image of ordered, rational procedure to external parties (Meyer and Rowan, 1977). In light of the importance of non-market actors in drug development — such as regulators, patient lobbying groups, and elected officials - it would be natural to conjecture that outsourcing reflects firms' need to insulate themselves from the conduct of the clinical trials process, so as to mitigate conflicts of interest. This does not appear to be the case. First, CROs do not shield pharmaceutical firms from responsibility for the integrity of the studies they sponsor (DHHS, 1997). In this regard, these suppliers are very different from accounting firms, who can be held liable for the accuracy of their audits. Second, pharmaceutical firms do not appeal to the certification rationale to justify their decision to outsource. Third, FDA medical examiners are often unaware whether a study they are reviewing has been outsourced, and to the extent that they become aware, tend to view externally-monitored studies with more skepticism, due to CROs' "sweatshop" reputation. ${ }^{3}$ Rather than the need for impartial certification, clinical development outsourcing reflects pharmaceutical firms' concern for the cohesion of their internal labor markets, as explained later in this paper.

The processing and analysis of biological samples constitutes the study's second setting; these activities take place in large facilities called central laboratories, whose emergence is a relatively recent phenomenon. In the 1990s, central labs progressively replaced smaller laboratories generally located in academic medical centers, for the FDA had come to expect greater reliability and consistency in measurement than the decentralized model allowed. With a focus on automation and real-time access to data, these suppliers might analyze large batches of diagnostic kits, extract DNA from patient samples, or provide storage facilities. This activity differs from the conduct and monitoring of clinical trials in that it has traditionally been fully outsourced by pharmaceutical firms. It is also much more capital-

\footnotetext{
${ }^{3}$ Personal communication with Dr. Murray Lumpkin, Deputy Director of FDA's Center for Drug Evaluation Research.
} 
intensive. However, these activities are similar along a number of important dimensions. First, the labor force is predominantly composed of non-professionals (clinical monitors in the first case; laboratory technicians in the second case). Second, relationships with CROs and central laboratories tend to be managed by the same set of people inside pharmaceutical firms. Figure 1 provides a summary schema of the organization of the clinical trials process.

\subsection{Clinical Development: Auspicious Setting for the Develop- ment of Embedded Ties?}

In many respects, clinical development resembles other economic activities that have been fertile ground for the emergence of "hand-in-glove" buyer-supplier relationships (Uzzi, 1997; Helper et al., 2000). This is not to say that extant theory predicts this should be the case here as well. Rather, past research would tend to support the more modest claim that contracting out an information-intensive activity through arms-length ties creates a number of hazards; complex contracts can mimic formal aspects of hierarchy, but cannot secure consummate — as opposed to perfunctory — cooperation from employees (Williamson, 1975; Stinchcombe, 1990).

Both settings differ from spot markets because they often involve ongoing interactions between the two contractual parties in the implementation process. They share a number of other characteristics. Consider first the provision of central laboratory services. Central Labs provide a critical input into clinical development whose quality is deeply dependent on the strength of the relationship between buyers and suppliers. One outsourcing manager explained:

"The same equipment is used throughout the study. When we file for approval, we do not have to explain why this or that value looked out of range. And we have invested a lot in IT to tailor our systems to capture data from their machines remotely, in real time."

Another one suggested:

"The lab must have specimen collection kits ready for the study sites to begin the trial. Because we tend to change study protocols early and often, sometimes up to the 11th 
hour, they often need to change, and reprogram, and reprogram. This means having additional staff on hand to absorb these last-minute amendments. Although labs are capital-intensive, the differentiator is labor. There is a pool of people that program the database and work with the investigators. Those people know what we expect and what are our processes, and how to translate this knowledge into a smooth operational ride."

The purported benefits of embeddedness are relevant in the second setting as well. Clinical study services require investments in specific human capital, rely on coordinated adaptation, and are made more effective by the transfer of fine-grained information and joint-problem solving arrangements (Uzzi, 1997).

Specific human capital. In clinical development, investments in human capital present both firm- and drug-specific characteristics. Cooperation among team members was deeply grounded in the particular routines used by the firm to integrate knowledge into collective action. Most pharmaceutical firms developed and refined processes that ensured compliance with regulatory guidelines, but this client-specific body of knowledge was rarely written down. Instead, it circulated among monitors as stories and snippets of advice. As a result, clients incurred non-trivial switching costs when selecting new suppliers. A clinical operations manager in one of the larger firm explained that

"If you work with a CRO, and they do a nice job for you, and they hit the milestones you wanted, why on earth would you look somewhere else? Because there are growing pains associated with setting up these relationships. If I go and work with a new CRO, I need them to understand the way I work and what I expect; moreover, I need to understand how they work. It's never easy. The first 6-8 months working with a new CRO are awful, because you are constantly stepping on each others' toes and miscommunicating."

Performance (generally measured by speed of trial execution, subject to a quality constraint for the data collected) was also heavily influenced by employees' ability to learn from the previous studies and apply this knowledge creatively during subsequent studies. Very often, this knowledge was contextual and hence not easily codified or rationalized:

"There are all the things that you have done but not fully documented, and you just wish you could pull a cassette out of the head of [our] project manager and implant it in the head of [the CRO's] project manager." 
Joint problem-solving and coordinated adaptation. Drug development is a sequential process: costs are additive, benefits are received only at the termination of the project, and the possibility of discontinuing development is ever present. Moreover, firms operate in a tightly regulated environment in which the boundaries between operational and scientific issues are constantly shifting and being redrawn under the pressure of external stakeholders. Because the "patent clock" of experimental compounds starts ticking shortly before entering the clinic, the challenge faced by pharmaceutical companies is to collect the information necessary to take the crucial "go/no-go" decisions about project cancellation in the shortest possible amount of time. This requires close coordination of scientific and operational decision making, which is generally best achieved by putting "heavyweight" product development teams in charge of specific projects (Clark and Wheelwright, 1992; Itoh, 1994). The team structure is designed to encourage ongoing cooperation and information pooling among team members, who represent different functional areas. Therefore, one would expect teams to span organizational boundaries; this expectation was shared by respondents. One clinical team manager claimed that he would "work best with CROs that felt like they were part of the team, that brought up issues, that came up with suggestions." Another added: "If I have an enrollment problem, the CRO should be the first to bring it to my attention... I would expect a CRO to have expertise and creativity, to be proactive, and to take ownership of most organizational issues."

Fine-grained information transfer. During the course of a clinical study, much useful information is generated locally by clinical investigators, either through direct interaction with patients or by purposeful analysis. This information — which may pertain to both the operational and scientific aspects of the study — is at risk of being "stuck" if it is not adequately captured in the study protocol. Since monitors are in contact with the complete set of doctors participating in a clinical study, they can bring information and problemsolving capabilities together at a single locus (von Hippel, 1998); this sometimes results in the production of idiosyncratic knowledge about experimental compounds and the diseases they are intended to treat. The Vice President for Clinical Affairs at a biotechnology company 
shared with me the experience of a clinical study team that illustrates the importance of "soft" information.

To perform a clinical trial for a drug used to treat pulmonary hypertension (a lifethreatening condition), this company recruited investigators from academic medical centers and private clinics. Puzzled by a very slow patient enrollment into the study, the clinical team leader asked the monitors to investigate and identify the root-cause of the problem. The monitors noticed a pattern in the patient enrollment statistics: the for-profit centers were lagging far behind the academic centers. Upon further investigation, the monitors determined that the delays were caused by the requirement that patients undergo a lung biopsy to determine their eligibility. In academic centers, this test could be performed and the results provided to patients on the same day, while in the private clinics, confirmation of eligibility was postponed for several days because of the need to ship biopsy samples to an outside laboratory for analysis. With this information, the study team amended the

protocol to substitute a type of specialized X-ray for the biopsy requirement. The ability to perform the screening of patients in a single day resulted in a much improved enrollment process. Interestingly, this team was not composed of CRO employees, but of in-house staff. A project manager in the same company added:

"An outsider should not be able to tell if a clinical monitor works for the company or the CRO. They are the eyes and ears of the company in the field. They write trip reports. They find out things that are going wrong, operational or medical. For example, the case report form might be set up poorly to gather the information. You need to read between the lines of the CRF. If there is something unexpected, if you're not out there finding out, you are going to miss it. Their job is to find out why a site is not recruiting well, for example. Is another company competing for patients? Is it the inclusion/exclusion criteria? Is it that the sites are not paid enough?"

\subsection{Have Embedded Relationships Emerged?}

As one might expect from this description, embedded ties appear to be a feature of the relationships between pharmaceutical firms and their Central Labs. Five of the six firms in the sample had succeeded in establishing relational contracts with a limited number of Central Labs. As recounted by the outsourcing manager of a large biotechnology firm: 
"Partnerships have worked with Central Labs. We get dedicated program managers that are ahead of the curve. The service level has gone up, costs have gone down, and they are getting more business... When we started that initiative, there were 7 or 8 labs in use. Each team had a preference, and moreover, they were quite likely to terminate the relationship with a lab after one project, switch to another lab, work with them for one or two projects, then terminate that lab because things were not working. From my standpoint, there was an absence of shared understanding and expectations. The teams did not realize what the labs needed to be successful. The hardest part was to build the trust in the initial projects. Once those had been successful, it was like a positive reinforcement loop. We are now doing $80 \%$ of our lab business with a single lab..."

In another firm, the manager in charge of laboratory services explained his approach in the following terms:

"One of the things we did going into it was to tell the lab that we were not going to guarantee a certain amount of business because we couldn't do it, the teams needed to have a certain amount of choice. But what we guaranteed is that we would only work with two labs. Their senior management believed us. That's a limited free market. They would be competing within a smaller pool."

In contrast, these six firms did not provide a single instance of a relationship with a CRO that could be characterized as "embedded." The differences between the two settings is all the more puzzling because the same individuals were in charge of managing relationships with CROs and Central Laboratories in all six firms. The transactional orientation of supply relationships manifested itself during the contract bidding phase, in the oversight practices used by pharmaceutical firms, and in the lack of enduring relationships between buyers and suppliers.

Competitive bidding appeared to be an accepted norm, with buyers usually organizing a "dog and pony show" where three or four CROs competed for one project. Most outsourcing managers lamented practicing "tactical outsourcing" or "just-in-time purchasing of CRO services," which they viewed as expensive and inefficient. Contract negotiations were often protracted, with suppliers attempting to limit buyer's ability to introduce future modifications, and buyers striving to maintain flexibility. Said one clinical department manager: "They want a protocol signed with your blood before they start working on a case report form." Of course, the unpredictability of ongoing development projects made contract 
renegotiation a near-certain occurrence, and conflicts over "change orders" often ensued. In the words of a project manager: "They try to milk you when they have you over a barrel because your trial is running."

Employee assignment was a significant bone of contention between buyers and suppliers. Outsourcing involved relinquishing a key decision right to CROs: the ability to match particular employees to specific projects. The identity, skill-level, and job design of CRO employees could not be easily contracted upon. In the words of an outsourcing manager: "CROs keep giving us bad people to choose from, and there is nothing I can do about it." Others highlighted instances where a team of seasoned veterans had been promised by a CRO, but "rookies" had been substituted for the "A-team" at the last minute. This "bait and switch" tactic appeared to be relatively common. Formal contracts did not solve the issue because buyers — or a court of law — could not distinguish voluntary turnover from opportunistic reassignment to another client.

The oversight practices of pharmaceutical sponsors were also indicative of a generalized distrust between buyers and suppliers. On this point, a clinical project manager said: "you don't just outsource, you devote $25 \%$ of the headcount to overseeing the outsourcing." The VP for clinical research at another company appeared to agree: "You still need internal FTEs to 'mind' the CRO because they tend to go off track." Of course, CRO teams resented what they call "micro-management" by "control freaks" and the arrogance of buyers who wanted them to adopt their own processes. To these objections one project manager replied that micro-management was the only way they knew to "get the CRO's attention." Another justified the intrusive brand of monitoring used by his firm in its interactions with CROs as follows: "They've got us on guard because they are always trying to pull a fast one on us."

Repeat business was a rare occurrence. All of the firms visited dealt with a very large number of CROs (24 in one case), and acknowledged they were constantly changing suppliers, even for projects pertaining to the same molecule. In the words of a clinical program manager: "It depends on how badly they screwed up on the last project versus the costs involved in 
bringing a new CRO on board." Another deplored: "We keep burning our bridges, going through learning curves because we are never satisfied."

The arms-length nature of buyer-supplier ties was colorfully described by a financial officer with overall responsibilities for contract negotiation. He explained:

"Our purchasing department uses a matrix where relationships can be described anywhere from a continuum that goes from 'used-car salesman' to 'We're married' kind of thing. For the used-car salesmen, we try to squeeze whatever we can out of the price, and we don't care if they go out of business, we do not care if they lose money, we are just trying to get the best deal we can, and of course the other side of that is 'We are going to grow together, we are going to give you business, you are going to give us better quality, faster, whatever.' And we are more on the used-car salesman end of the spectrum. I think that's the case for most sponsors. I think that Merck and Pfizer are even tougher with the CROs than we are. Gosh! We're pretty tough on those guys, you know."

It is possible to cross-check the field evidence with data from the sample of contracts mentioned above. Following Uzzi (1996), I start by computing a Herfindahl index of spending concentration. The dollar share of each supplier in the portfolio of a given buyer is computed, and the index is obtained by summing the squares of these shares, yielding a number between 0 and 1. The mean Herfindahl index is 0.34 , and the standard deviation 0.21 (the distribution is graphed in Figure 2). According to this traditional measure, on average pharmaceutical firms maintain a network of exchange partners equivalent to the structure that would obtain were they to split their spending equally across three CROs. This seems at odds with the field evidence, but the Herfindahl index suffers from a serious shortcoming. For a number of pharmaceutical companies in the sample, there are relatively few observed projects. This fact makes it difficult to distinguish "true" spending concentration (as a feature of buyers' choice of suppliers) from lack of actual variation due to insufficient opportunity to observe contracts for a large number of projects. Companies that conduct only a few trials will tend to exhibit high values of the Herfindahl, but that is not necessarily indicative of genuine high concentration. 
An index of spending concentration that adjusts the traditional Herfindahl for the "small number" problem is based upon the work of Ellison and Glaeser (1997). It is computed as:

$$
\frac{\# \operatorname{CONTRACTS} S_{i}}{\# \operatorname{CONTRACTS} S_{i}-1} \cdot\left[\frac{\sum_{j}\left(S H A R E_{i j}-x_{j}\right)^{2}}{1-H E R F_{0}}-\frac{1}{\# C O N T R A C T S_{i}}\right]
$$

where $i$ indexes buyers, $j$ indexes suppliers, $S H A R E_{i j}$ measures the share of company $i$ 's contract volume allocated to supplier $j, x_{j}$ measures CRO $j$ 's market share, \#CONTRACT $S_{i}$ denotes the total number of contracts awarded by firm $i$, and $H E R F_{0}$ refers to the Herfindahl index of the contract research industry as a whole: $H E R F_{0}=\sum_{j} x_{j}^{2}$. The mean for the Ellison-Glaeser index is -0.084 with a standard deviation of 0.137 . Essentially, the distribution is a spike centered at 0 (see Figure 3): When corrected for "fewness," spending by pharmaceutical firms in drug development appears just as concentrated as what one would expect were these companies to sprinkle their spending according to the distribution of CRO market shares. ${ }^{4}$

\subsection{Rise and Fall of Preferred Provider Agreements}

The respondents appeared to be acutely aware of the existence of more relational modes of exchange in other industries. I discovered that some companies had endeavored to move away from arms-length relationships, but these efforts had uniformly ended in failure. During the mid-1990s, the industry was abuzz with talks of "partnerships" between pharmaceutical sponsors and CROs. The hazards of arms-length contracting were keenly felt by both buyers and suppliers, and this led some firms to enter into long-term supply arrangements, so-called "Preferred Provider Agreements" (PPAs). Three pharmaceutical companies in the sample had recently experimented with such relationships, but I also relied on testimonies from CRO employees to get a more complete picture.

While parties to PPAs felt the need to couch their shared understandings in a formal contract, their initial dispositions appeared to have been consistent with the spirit of relational

\footnotetext{
${ }^{4}$ Unfortunately, comparable data pertaining to transactions between pharmaceutical firms and central laboratories are not available.
} 
governance (Macaulay, 1963). The outsourcing manager of a pharmaceutical firm that had entered into two PPAs in 1994 recalled:

"We wanted to get money out of the picture, because in the end it's not the contract that is the most important. So the deal was that we were not going to quibble, we would pay whatever they were going to bill, and we would simply get a discount on their hourly rates."

In the words of a project manager at this firm:

"The goal was to tell companies to take a product from Phase II to Approval. That means that they have $X$ number of people dedicated to you. That was the goal. The problems is that a Phase II will start and stop, start and stop until they finally figure out what the drug does. When it stops, what do you do with these dedicated people? This happened in one instance when drug supplies were unavailable for a long period. We nearly called off the agreement, because you have to pay them to sit around and do nothing. We used the preferred providers for two large projects. Moreover, a lot of internal problems at one CRO had an impact on the work. The most knowledgeable people left the firm, and quality went down. Billing became a nightmare with both CROs. People were thinking that they should bill you when they think of you - like lawyers. There were change orders all the time, and we just had no control. They were asking us to predict 5 years ahead of time what their pipeline was going to look like. We could not even do it with a five months time horizon! That was supposed to save us money, but in the end that did not materialize."

The CEO of a small CRO agreed that the idea behind PPAs was to select CROs "based first on cultural compatibility, second on therapeutic capabilities, and only third on price." In an account relatively consistent with that of buyers', he went on to add that

"... in the end, it was just price. CROs discounted their prices to get into these agreements. That meant they had no incentives to put their best people on these projects. Moreover, there were some spectacular project cancellations, and nobody heard from preferred providers ever since."

In a large biotech firm who also experimented with PPAs (in this case formally structured as a five-year payment guarantee), the proximate factors leading to the demise of the relationship are murkier. There, the agreement was negotiated by top management in ways that antagonized clinical study teams and hampered the spirit of cooperation necessary for the agreement to succeed: 
"We became very dissatisfied with the job they were doing. They did not really need our business, because the CRO industry was growing so fast at that time. And our teams did not want to select them. Moreover, new teams became involved, and the CRO did not have the breadth of therapeutic expertise we needed."

Of course, these quotes raise more questions than they answer. Why did CROs took advantage of these agreements when they could have been enticed to cooperate by the prospect of repeat business? Why did clients use PPAs as a backdoor device to squeeze suppliers on price? And why did they refrain from doing so with Central Labs? To answer these questions, I turn my attention to differences in the organization of work inside pharmaceutical firms, Central Labs, and CROs.

\section{$5 \quad$ Internal Firm Structure and the Embedding Process}

The fieldwork enables me to draw two different comparisons. First, Central Labs' internal labor markets can be evaluated against those of CROs. Second, CROs' internal labor markets can be contrasted with those of pharmaceutical firms, since there exists inside the latter employees engaged in exactly the same activities as inside the former. I refer to "internal labor markets" not only in the traditional sense of hierarchical job ladders (Doeringer and Piore, 1971), but also in a broader sense encompassing a company's overall human resource strategy — wage policies, job classifications, and rules regarding the deployment of labor and employment security.

Pharmaceutical firms and Central Labs bore the hallmarks of the "posthierarchical workplace" (Zuboff, 1988) or "high-commitment organization" (Osterman, 1994) - a conception of work reliant on a collective effort conducted by self-managed teams of diverse skills, working with considerable discretion, judged on results and outcomes (Powell, 2001). In contrast, CROs provided a modern example of Taylorist organizations - detailed hierarchical divisions of labor with at their core employees focused on narrow and specific tasks and a clear distinction between conception and execution. The former preserved and transferred knowledge through extensive training within communities of practice (Barley, 1996) and had adopted "high-performance" work practices designed to elicit greater employee involvement 
in the workplace (Pil and McDuffie, 1996); the latter used formal rules and procedures to achieve coordination. The training manager at a large biotechnology company probably best described the essence of the "transformed workplace" prevalent inside most pharmaceutical firms:

"A team is worth many times more than any function. As long as that team is vibrant, alive, and functioning, everything is fine. If that team goes away, then team members feel very lost... The role of the leader is to harmonize the inputs of different people. A lot of decisions are reached by consensus, e-mail, or corridors. The decision-making is not as crisp or formalized in ways that you may find at other companies. That often means that taking decisions is a long process. But our approach is that decisions should be taken at the lowest competent level."

In interviews with clinical monitors inside pharmaceutical firms, the majority had had earlier experiences working for a CRO. Revealingly, these ex-CRO employees used the term "data mules" to refer to clinical monitors working for CROs. They reported having been lightly trained and strenuously overworked (including travel four or five days a week). One asserted: "When I was working for a CRO, I was there strictly to pay my dues so that I could be hired by a pharmaceutical company." A business development director at a mid-size supplier concurred, conceding that

"Being a clinical monitor is not a lifetime career, it is a stepping stone to other jobs in the pharmaceutical industry. In a pharma firm, employees get attached to a specific product, or at least a specific therapeutic area; they develop a sense of ownership because it is possible to see the development of a product from start to finish. If you work for a CRO, you see a little piece of everybody's pie, it is much less exciting."

As a result, employees of pharmaceutical firms in similar roles tended to be older, more experienced, and better trained. Career patterns differed as well. Pharmaceutical firms combined the horizontal division of labor characteristic of "functionally flexible workplaces" (Kalleberg, 2001) with lateral mobility that enabled employees to develop career trajectories along vertical job ladders. The following anecdote, culled from my field notes, best captures the robustness of their internal labor markets. On my way to lunch during a site visit at a large pharmaceutical firm, I stumbled across a large crowd assembled in the atrium for a ceremony recognizing employees of the "Class of 1980." I asked my host what the number 
1980 referred to, and he replied in all seriousness that those employees had first joined the firm 20 years hence. I found revealing the fact that a large corporation would cultivate such an institution; even more telling was that a large fraction of the employees who had joined the firm that year were still employed there 20 years later. To be sure, my informants' tenures were generally shorter at other firms, but they were invariably longer than those of front-line CRO employees I conversed with. One outsourcing manager characterized CROs as "high attrition workmills." Complaints about monitor turnover became a mantra; the topic invariably came up as an issue in my interviews:

"We had a project where we had 100\% turnover" [VP Clinical Development]

"This turnover thing is going to kill them" [Clinical Operations Manager]

"It seems like it's a revolving door!" [Project Manager]

My respondents inside CROs acknowledged that short tenures were the norm for all but the most senior positions. For instance, the owner of a small CRO asserted that the annual turnover rate in the industry is $25 \%$ to $30 \%$ on average. He added: "That is very high if you think that most clinical trials last at least a year... It is a very competitive industry, nobody can afford to raise wages." The rate of voluntary turnover for Central Lab employees was much lower - 5\% according to a large supplier's sales manager. He further boasted, in an obvious jibe at his CRO colleagues: "I'm not grooming people for [Eli] Lilly."

The picture that emerges is one where weak internal labor markets for suppliers are associated with arms-length ties between buyers and suppliers. Is this association spurious? The mechanisms through which internal firm structure influences the embedding process are explored below. Weak internal labor markets undermine embedded ties because of (1) their exclusive reliance on "hard" measures of performance, (2) job designs inimical to teamwork, and (3) the hierarchical constraints they put on information flows.

Misaligned incentives. CROs earn their "sweatshop" reputation by using narrow metrics of job performance to reward (and punish) individual employees. Project-level measures of performance have two distinct effects on the productivity of CRO teams. First, they skew clinical monitors' attention and effort away from knowledge production towards data- 
processing tasks. An outsourcing manager described the unbalanced incentives of CRO employees in these terms:

“...There is a line-by-line definition of the CRO's responsibilities. That means that the CRO is less likely to notice stuff that might be going on at the sites. There are no incentives for the individuals at CROs for capturing 'soft data', unlike here, where you get rewarded at every level. At a CRO, you might work for two or three sponsors at the same time. So it's all about hard deliverables. Anything beyond the contract you do not get."

Second, what could be measured easily in the supplier's hierarchy was often several steps removed from what clients ultimately valued. In particular, CROs put great emphasis on speed of execution for every task, partly because this could increase employees' billable hours, and partly because suppliers often suffered financial penalties when they did not complete projects on time. However, this emphasis could have unintended consequences. A project manager provided the following example pertaining to the investigator selection process:

"...[Inside the CRO] it does not pay to be honest. The people doing the recruiting for CROs do not have a clue. They do not understand medicine, so if a private doc tells them they are going to recruit 24 patients, they will believe him, even though this is clearly ridiculous. For the CROs, this is simply a numbers game. Site selection is done in a hurry. The employee will simply say: 'I recruited all the docs I needed today.' It is all about meeting deadlines, even though the sponsor may end up with the worst set of investigators."

Unbalanced incentives (Holmström and Milgrom, 1991) and distortionary performance measurement (Kerr, 1975; Baker, 1992) interfered with the embedding process because the behavioral pathologies they created could not be mitigated at higher hierarchical levels. In this respect, CROs differ from the garment manufacturers studied by Uzzi (1997). These suppliers are not known for their vibrant internal labor markets, but this need not hinder the emergence of embedded ties as long as performance measures are not distortionary and valuable 'soft' information resides at the top of the hierarchy.

Multiproject job designs. The organization of work differed inside pharmaceutical firms and CROs. A project manager at a CRO confided that "in order to get the optimal utilization, the pool of monitors needs to be common across therapeutic areas. Otherwise there are silos of staff and people are being under-utilized." Indeed, CROs maximize short-run profits by keeping their employees fully "billable," which often meant assigning them to multiple 
projects at a time, and shifting them laterally from project to project as the need arose. In contrast, in-house monitors were generally assigned to a single project at a time, and specialized therapeutically. Furthermore, assignment decisions took idiosyncratic expertise into account. For example, if a monitor had worked on previous studies for a drug, he/she was very likely to be assigned to the follow-on study as well. Inside central labs, employees worked on multiple projects, but staff was organized in self-directed teams dedicated to specific clients. The knowledge enabling effective practice was distributed among employees, and the subculture's rules for accessing distributed expertise were an important ingredient of successful problem-solving strategies. Accordingly, single project/client assignments contributed to preserve interpersonal relationships that made teamwork effective (Jacoby, 1999; Gant et al., 2002). It also fostered a sense of identification with the product under development. In-house and CRO teams differed in the extent to which they displayed what practitioners called the "sense of project ownership." A project manager described the state of mind of CRO teams as follows:

"...once the trial is under way, your crisis is not theirs. You are probably more attached to that product than they are. You are involved in all of it, but they only get this small piece. They are not getting the full picture."

At a large pharmaceutical firm, in-house clinical monitors specialized therapeutically, except in the early stages of development, as it was felt that safety trials required expertise that cut across therapeutic areas. A monitor in the early stage unit found emotionally painful the need to "disinvest" molecules that had progressed past the initial safety hurdle for which she was responsible:

"I am always wondering what has happened to compounds I have worked on and have gone over to later development. It becomes part of you. That's a year or two of your life. It is a little bit unfortunate that you have to hand it over. Some of the people in our group are actually transferring to the therapeutic areas to follow the compound... The success of a compound reflects back on you and the work you do."

Stilted communication channels. Weak internal labor markets are also characterized by their emphasis on formal reporting mechanisms. When all communication must flow through 
a rigid chain of command, fine-grained local information, even if acquired by suppliers' staff, is less likely to find its way to the buyers' employees who can use it most effectively. In the words of a project manager:

"The bigger the CRO, the more information gets filtered before it reaches the sponsor... The CRO is a business. They don't have the time to develop a rapport with the staff, the study coordinator or the investigator, to elicit some of this [soft] information. They are there, they are looking at the source documents, they are checking the CRFs, the regulatory binders, but that's all they do. The trip report is where we could get that kind of stuff. But depending on how you set up the project, they may call their supervisor who calls their supervisor, who eventually calls the project manager. By then, the information is likely to be lost because they do not have a sense of ownership for the project."

This last quote highlights the overall goal conflict between buyers and suppliers. Inside pharmaceutical firms, managers strive to produce all the information required to reach the correct "go/no-go" decision for a particular drug, subject to a budget constraint which includes "time costs" (i.e., foregone sales opportunities because the drug, whose patent clock is ticking, lingers in development). Due to the severe penalties for late performance contained in many outsourcing contracts, CRO managers focus instead on time-to-project completion (subject to the constraint that data quality had to exceed some minimum standard). This lack of congruence between managers' objectives on either side of firm boundaries reinforced work behaviors among CRO employees that reduced the overall attractiveness of relational governance while increasing opportunities for conflict between exchange partners. Most saliently, employees engaged in "chunking," whereby each task was partitioned in ways that improved measurable performance within tasks at the expense of a soft-handover between tasks. In the words of a frustrated clinical operations manager at a major biotech firm:

"Think of the various steps that are needed from protocol development, site initiation, enrollment, data collection, database lock, analysis, and final study report. The way CROs do this is: you finish one, then you start the next one, then you start the next one, etc. This mentality, while it is great to make sure that you are charging people the right amount of money, that you can defend your position, it's a killer in drug development. Within site initiation, there may be about eight processes that go on. Come up with a template questionnaire, come up with a template contract, come up with a consent form, etc. They do not do all of these processes concurrently. They like to do one, finish it, then start the next one." 
These observations provide the first hint that arms-length ties between CROs and pharmaceutical firms are both a cause and a consequence of weak internal labor markets within suppliers. Chunking reflected suppliers' obsession with narrow and measurable measures of job performance, but the practice was also reinforced by the structure of outsourcing contracts; and this structure was itself an expression of the transactional orientation prevailing between buyers and suppliers. The financial officer of a mid-sized pharmaceutical firm recounted his firm's initial experience with "time and materials" contracts. Such cost-plus contracts had the virtue that they did not create incentives for suppliers to skimp on quality. However, they created opportunities for CROs to "lowball" their bids and overcharge clients later for "scope changes." As a response to these pathologies, the firm had adopted so-called fixed-units contracts. The tasks to be performed by the supplier were broken down to a very detailed level (some contracts included more than 200 items), and each unit was then priced independently. According to this manager, the results had been dramatic:

"When we realized TEMM was nuts, [Consulting Firm X] came up with what they call fixed-unit pricing that says: 'show me deliverables.' What I want to pay for is a monitoring visit, a case report form entered, a statistical analysis. And you assign a price for each of these units. Now the CRO says 'This month I did the following things for you' and now our clinical people can say 'Yeah, they entered a thousand pages, yeah they cleaned 500 pages.' I know what I got for my money. The CROs are completely held accountable. It's a great system for them to bid properly, and now they must run an efficient shop."

This contractual innovation effectively rid buyer-supplier relationships of the problem of insincere bidding strategies and artificial scope changes, but played right into CRO employees' predilection for chunking. Since the costs induced by chunking were less transparent and more diffused than those caused by scope changes, fixed-unit contracts had been broadly adopted in the industry. Front-line personnel, however, were under no illusion that tinkering with the structure of formal contractual arrangements could change the nature of these supply relationships.

What the evidence above supports is not so much the idea that weak internal labor markets "cause" embedded ties to fail than the idea of organizational complementarities: arms-length contracting between firms raises suppliers' returns to structuring the employ- 
ment relationship along Taylorist lines. Weak internal labor markets in turn obviate the need to adopt relational modes of exchange. This vicious circle results from a self-fulfilling failure of expectations. Before discussing this idea in more depth, two questions arise. First, if outsourcing the coordination of clinical trials is so inefficient, why is the practice so prevalent? Second, why have pharmaceutical firms and CROs failed to change this configuration of relationships to adopt the more successful configuration that prevails between pharmaceutical firms and central labs?

\section{Clinical Development Outsourcing in the Shadow of the Future}

In addition to job ladders, new structuralist accounts of the labor market emphasize the importance of psychological contracts - perceptions regarding mutual obligations between employers and employees — as a source of employee motivation (Baron, 1984; Rousseau, 1995). External changes such as globalization and deregulation are often alleged to have undermined the standard employment relationship in which job security was exchanged for loyalty (Cappelli, 1999; Neumark, 2000). Yet, shared expectations of continued employment

are also found inside "posthierachical workplaces," since the successful adoption of highperformance work practices presupposes the ongoing consent of front-line employees, and this consent is unlikely to be forthcoming if their working lives unfold in the shadow of downsizing. This poses an important challenge for firms operating in fast-paced, knowledgeintensive industries. On the one hand, an employment relationship reduced to its formal and transactional aspects is likely to hamper firms in these environments as they strive to reduce cycle times and increase productivity. On the other hand, the uncertainty that is characteristic of product and labor markets in technology-intensive industries makes it difficult for firms to commit to long-term employment. This dilemma is particularly salient in clinical development. Drugs enter and exit the pipeline early and often, creating wide variation in the number of employees needed to staff the development functions within the firm (Azoulay, 2003b). 
The Buffering Role of CROs. Pharmaceutical firms appear to have turned to CROs precisely to handle this variability. By buffering a core of insiders with a periphery of contractors bearing the brunt of workload adjustment, the firm lifts the shadow of downsizing from before the eyes of its staff, credibly signaling its intention to deliver on a promise of job stability. As a result, insiders were more likely to engage in the kind of behaviors conducive to the creation of specific knowledge. The use of outsourcing as a buffering mechanism probably explains why senior managers displayed an overt bias in favor of internal teams: "If resources were not an issue, we would never outsource" captures the spirit of comments often heard at the highest echelons of pharmaceutical firms' clinical development operations. ${ }^{5}$ Since resources were an issue - hiring and firing insiders to follow the vagaries of the development pipeline was not viewed as a viable option - pharmaceutical firms used outsourcing as a commitment device to their own staff. This idea was articulated, in one form or another, by at least one manager in every firm I visited. The argument also resonated with inhouse monitors - the beneficiaries of this unusual insurance mechanism. Below are two representative quotes:

"... if you hire somebody here, you hire him for 40 years, and you have to give him work for 40 years. Otherwise you may lose the team esprit-de-corps. People here are incredibly committed. You see them doing heroic acts to support the team. Even if we did not think about it that way initially, outsourcing helps maintain continuity for our own people." [Training Manager]

Or: "I would hate working for a CRO. They really have to be worried and keep everyone on their staff busy. But that's precisely why you hire a CRO - because you do not want to lay off half your staff if an indication is canceled... " [Junior Clinical Monitor]

Of course, suppliers understand perfectly that "the essence of a CRO contract is that in 30 days, you can be out of here" (in the words of an outsourcing manager at a large biotech firm). Moreover, buyers are aware that they are in part responsible for the lack of cooperation on the part of CROs:

\footnotetext{
${ }^{5}$ This stands in contrast with Eccles and White's evidence on transfer-pricing arrangements within multidivisional firms, where the conflict between internal and external supply is used to elicit cost information that would remain buried inside the organization in the absence of conflict over supply sources (Eccles and White, 1988).
} 
"The hire and fire model for CROs really gets in the way of forming stable relationships and growing the pie over time. At the end of the day, we want to be able to fire them when we don't need them. That's the primary thing we want. Although we have a scale-down process as part of our contracts, it is very limited." [Outsourcing Manager]

The sales director of a large CRO concurred: "Because we have low expectation of repeat business, we are reluctant to commit teams to particular clients." Added another:

"Contracts have a 60/90 days cancellation clause. So we assume a lot of risk. We are mindful of it, and that has an impact on contract negotiations. Relationships can actually hurt you in this business."

In light of this evidence, the efforts devoted to engineer embeddedness between buyers and suppliers appear somewhat quixotic. Besides CROs' buffering function, additional hurdles hampered the emergence of embedded ties in clinical development.

The Failure of Generalized Reputations. Embedded ties between CROs and pharmaceutical firms might embody a qui-pro-quo of the following form: "If you go beyond the letter of the contract and choose to dedicate staff to our projects, then we will award your firm more contracts in the future." Unfortunately, buyers and suppliers face large temptations to renege on such an implicit contract. For example, if the pipeline suddenly dries up following the simultaneous failure of a few experimental compounds (a common occurrence), then the pharmaceutical firm will rely on its core of insiders to handle the remaining demand for clinical services. Fully aware of this fact, the CRO will often renege on its promise to dedicate staff if a more profitable assignment opportunity arises for some of its employees. Because the shadow of the future does not loom large enough, the cooperative outcome does not materialize; buyers and suppliers revert to inefficient spot outsourcing contracts.

This dilemma does not arise with Central Labs. Not only is there no source of internal supply, but in addition there is less uncertainty regarding the future value of suppliers' specific investments, as the locus of specificity tends to be at the client level, unlike the case of clinical services where the project- and drug- level is more relevant. Since the probability of failure for a particular client is much lower than the probability of failure for a particular 


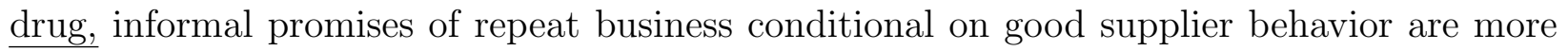
credible than in the clinical development setting. At a large biotech firm, an outsourcing manager contrasted partnerships with CROs and Central Labs in the following terms:

"We are talking outsourcing programs as opposed to studies - although we will not guarantee anything. But we could share with them what's in our pipeline. What is the workload coming in the next six months? Are they willing to dedicate quality people to our programs? The deal is that we will commit to continue to use them if their performance rises to our expectations. That has worked with Central Labs. We get dedicated program managers that are ahead of the curve. Service level has gone up, costs have gone down, and they are getting more business. But the labs are in a much less risky position than the CROs."

However, the failure of bilateral reputation mechanisms cannot by itself explain the dearth of embedded ties. Recent theoretical work in economics and sociology has demonstrated that changing partners itself is unimportant; the crux of the matter is information transmission among exchange partners about past behavior (Raub and Weesie, 1990; Kandori, 1992; Bendor and Swistak, 2001). At first glance, there would appear to be scope for effective multilateral enforcement in addition to unilateral sanctions (e.g., a buyer deciding not to award future contracts to a $\mathrm{CRO}$ at any point in the future). For instance, a pharmaceutical firm could attempt to ruin the reputation of a particular CRO by communicating its poor record to other pharmaceutical firms. Industry groups such as the Pharmaceutical Outsourcing Managers Association could provide the appropriate conduit for such information. In practice, punishments of defectors by the "community" of pharmaceutical firms was difficult because high turnover inside CROs undermined the informativeness of past performance records. This idea is encapsulated in a piece of industry wisdom often heard during the field work: "A CRO is only as good as its last contract." To justify this dictum, a project manager explained:

"We have not had examples of enduring good matches - mostly because CRO people turn over so quickly. Sometimes, with a single vendor who handles two projects simultaneously, the first one is a huge success, the second one is a horror story."

While the observed correlation between the shadow of the future and the extent of interfirm cooperation is consistent with standard repeated-game arguments, understanding the 
mechanism leading to the breakdown of relational governance requires opening the black box of internal organization, and acknowledging the distinction between the reputation of individual agents and that of their organization's.

In summary, the absence of "partnerships" so often deplored by buyers and suppliers cannot be understood in isolation from other contractual arrangements, both implicit and explicit, within these same firms. Pharmaceutical firms' internal labor markets would probably be less vibrant in the absence of the buffer provided by seemingly inefficient spot outsourcing contracts with CROs. Furthermore, buyers could and did mitigate the inefficiency of arms-length ties by allocating to external teams projects for which they expected misaligned incentives, stilted communication flows, and multi-project assignment to be less damaging (Azoulay, 2003a).

\section{Discussion}

Many of the features of the complex environment in which buyers and suppliers evolve are determined simultaneously. The failure of embedded ties in clinical development should be viewed not as the result of some fundamental economic parameter or the reflection of some underlying socio-cultural values, but as an interacting "equilibrium" that hangs together, precipitated by expectational inertia (Greif, 1998). For instance, one might believe that arms-length ties between pharmaceutical firms and CROs are justified in light of the fact that routine projects tend to be allocated to CRO teams. But if clinical development outsourcing deals were more akin to embedded relationships, one would expect the allocation of projects between inside and outside teams to change as well. In particular, it would become less costly to outsource knowledge-intensive projects to CROs.

Similarly, one might explain the dearth of embedded relationships by appealing to CROs' high turnover rate. The evidence presented above suggests that this view is misguided. If embedded relationships existed, there would be opportunities for differentiation on the basis of quality in the clinical services industry, suppliers would be in a position to extract 
economic rents, pay employees above-market wages, and retain them more effectively. This would further buttress "hand-in-glove" supply relationships. The allocation of talent within buyers and suppliers, the extent of reliance on a buffer of external teams, and the degree of competition in the upstream sectors are likewise endogenous variables, and should not be misconstrued as independent levers under the control of exchange partners. Figures 4 and 5 provide summary schemas of the constellation of relationships for the two settings studied in this paper.

An alternative interpretation is that variation in pre-existing social ties between employees on both sides of organizational boundaries accounts for the contrasting patterns in supply relationships I observed. Previous organizational research often describes embedded business relationships superimposed on a preexisting network of family, ethnic, or friendship ties (Bailey and Waldinger, 1991; Uzzi, 1997; Ingram and Roberts, 2000). There is more to embeddedness than interpersonal affect, however, since social relationships appear to play a greater role in structuring exchange when anticipated economic benefits are relatively high (Zhou et al., 2003; Ingram and Lifschitz, 2003). In comparison with the settings that have been the focus of past research, supply relationships in drug development were probably less imbued with social meaning overall. Furthermore, social contexts were very similar across the two settings. For example, the extent of friendship ties between buyers' and suppliers' employees did not appear to vary significantly. As well, employees of CROs and Central Labs were drawn from closely-related, non-professional labor markets. With one foot in the material world and the other in a world of representations, both categories shared the characteristics of technical occupations vividly described by Barley (1996). Of course, this lack of variation also means that the evidence presented above cannot be used to adjudicate claims regarding the relative importance of the "shadow of the past" and the "shadow of the future" for the ability of economic actors to sustain cooperative outcomes.

I examine three alternative constellations of relationships to organize exchange: dual internal labor markets, portfolios of buyer-supplier relationships, and "discrete" outsourcing. None of these arrangements were actually observed during the fieldwork. I use the available evidence to speculate on the reasons for this lack of institutional variation. 
Dual Internal Labor Markets. Could pharmaceutical firms maintain a separate division of "peripheral" employees subject to different rules than those applied to the core labor force? Such dual internal labor markets - in which outsiders are confined to a separate division within the same legal entity - are inherently unstable. Courts may not grant firms the right to apply different termination policies to workers sharing the same narrow job description, even if actual job requirements differ substantially between the two categories of employees. This institutional constraint has become increasingly binding over time in the United States, where the "employment-at-will" doctrine has been undermined by state courts (Autor, 2001). There exists a deeper reason confining the periphery outside of organizational boundaries: equity norms may cause two-tiered internal labor markets to perform poorly, especially in team-production settings (Lazear, 1989; Baron and Pfeffer, 1994).

A comparison between CRO employees and so called "freelance monitors" provides additional insights on the feasibility of dual internal labor markets. Pharmaceutical firms used independent contractors for reasons unrelated to buffering and the need to adjust the size of the labor pool in the face of pipeline uncertainty. Freelancers were highly-skilled professionals who frequently monitored multiple studies for the same firm, and were assigned to projects for which they possessed specific expertise. One manager in charge of a network of regional monitors asserted:

"CRO employees are generally the least involved, the least interested, and the most task-oriented. They don't add much value. The independent is an interesting animal because they tend to be far more experienced than even our own employees. They've seen so much that they are able to smell something fishy from miles apart."

Independent monitors differed from $\mathrm{CRO}$ employees in two essential respects. First, like the IT professionals studied by Kunda et al. (2002), they had chosen self-employment. Second, their independent status removed a layer of agency between the firm and the employee. As a result, clients could assign freelancers to projects as they saw fit, and this ability effectively brought contractors within the reach of pharmaceutical firms' incentive systems. For legal reasons, client firms were weary of commingling their own workforce with skilled contractors, and as a result had endeavored to create artificial barriers separating perma- 
nent from contingent employees. These barriers could be either physical (deploying monitors on a regional basis with minimal presence in the firm's central location) or administrative (contracting with specialized agencies).

Portfolio of buyer-supplier relationships. Another possibility would be for pharmaceutical firms to sort their suppliers into different tiers, with the outer tiers being afforded less insurance against pipeline shocks than "first tier" suppliers. This pattern has been observed in other industries, most notably in the Japanese automobile manufacturing (Ansanuma and Kikutani, 1992; Bensaou, 1999). Uzzi (1996) also documents a plurality of ties between buyers and suppliers in the New York better dress industry, with only a handful of embedded relationships within the portfolio of any given buyer. However, in these examples the existence of an internal supplier is not discussed.

Among the six firms I visited, I found only one isolated instance of a relationship with a particular CRO that could be characterized as "hand-in-glove." Interestingly, this firm is the same that had tried (and failed) to implement preferred provider agreements with two large CROs. While the former approach could be characterized as "embeddedness from the top-down," the special relationship this large firm enjoyed with this small CRO would fit better under the label "embeddedness from the bottom-up." A manager in charge of the company's training facilities told me that

"CRO X got its first contract with us in 1995. Ever since, they've done 32 projects. They dedicate a team to the compound. The only way that the team gets broken up is if a person leaves the company. That makes us more committed to the relationship. We would need to strengthen it, but we've been burned by the PPAs and we told them that we are not making commitments anymore. This is like a PPA without the legalese, and it was not negotiated at the VP level, which actually kills the partnership."

However, these accomplishments appeared very fragile. This firm's outsourcing manager challenged the assertion that the relationship of his company with CRO X was substantially different from the relationships it entertained with other CROs:

"CRO $X$ is not that phenomenal, they are really nothing special. We get along with them, they are a nice CRO, but it's a crapshoot. On the next study they could be 
terrible. You just don't know, there is no long term trust in this business. If you hit something that looks like a good match, you are going to continue - until they underperform. Then you reset the counter to 0."

In drug development, the proposition that the largest firms could provide some insurance against pipeline shocks to a narrow set of carefully-selected suppliers has some face validity. However, it is possible that conditional on retaining a core of insiders, no firm is large enough to provide this kind of insurance to suppliers, given the amount of uncertainty involved in clinical trials.

Discrete Outsourcing. So far, the discussion of clinical development outsourcing has taken the existence of a core of insiders inside pharmaceutical firms as given, but in discussing alternative governance regimes, it is useful to relax this assumption. Why do these firms not fully devolve the coordination of clinical studies onto a few CROs, with whom they could develop embedded ties? This possibility can be most fruitfully explored by focusing on the experience of start-ups. These firms should be less constrained by their core of insiders than established pharmaceutical firms. In the sample, only one firm could be considered small enough to qualify as a start-up (as it had not brought to completion the development of any product as of July 2000). I found no differences in the relationships of this firm with CROs compared to those of larger firms. The outsourcing manager rationalized this situation by reasoning that his company was too small for the perspective of repeat business to provide incentives for contractual performance, as suppliers were aware that a reasonable chance existed that the firm might not be in business in the future. As a result, this firm was fast developing in-house clinical capabilities, hiring its own staff to oversee and monitor clinical trials.

\section{Conclusion}

I have set out to achieve two goals: to characterize the nature of buyer-supplier relationships in drug development, and to identify the major social and organizational impediments to the emergence of embedded supply relationships. Using qualitative methods, the study 
contributes a number of findings that hold significance for the study of interorganizational networks.

In order to explain why economic actors often fail to structure exchange in networks, past research has emphasized the hazards of "overembeddedness" (Uzzi, 1996) and the difficulties involved in engineering relationships in the absence of a pre-existing network of ethnic, family, or friendship ties (Ingram and Roberts, 2000). While acknowledging the merits of these explanations, I focus on the structure of constituent firms' internal labor markets and show how the nature of the employment relationship powerfully shapes and constrains the scope of interorganizational networks. In particular, weak internal labor markets hinder the embedding process by misaligning incentives, stultifying rich information flows, and fostering job designs inimical to teamwork.

The paper also provides a re-interpretation of recent structuralist accounts of the labor market (Kalleberg, 2001; Cappelli and Neumark, 2002). Outsourcing "non-core" activities while relying less on shared expectations of continued employment is often thought to be antinomic with the adoption of high-involvement work practices, which presume employees' ongoing decision-making involvement. The analysis above suggests that these practices might be instead mutually reinforcing: In fast-paced product markets, partial outsourcing using seemingly inefficient spot contracts might provide the necessary stability required for horizontal divisions of labor to thrive; in such settings, embeddedness within firms might come at the expense of embeddedness between firms. 


\section{References}

Ansanuma, B., and T. Kikutani.

1992 "Risk Absorption in Japanese Subcontracting: A Microeconometric Study of the Automobile Industry." Journal of the Japanese and International Economies, 6: 1-29.

Autor, D. H.

2003 "Outsourcing at Will: The Contribution of Unjust Dismissal Doctrine to the Growth of Employment Outsourcing." Journal of Labor Economics, 21: 1-42.

Axelrod, R.

1984 The Evolution of Cooperation. New York: Basic Books.

Azoulay, P.

2003a "Acquiring Knowledge Within and Across Firm Boundaries: Evidence from Clinical Development." Working Paper, Columbia University.

2003b "A Portfolio Approach to Transaction-Costs Economics." Working Paper, Columbia University.

Bailey, T., and R. Waldinger.

1991 "Primary, Secondary, and Enclave Labor markets: A Training Systems Approach." American Sociological Review, 56: 432-445.

Baker, G.

1992 "Incentive Contracts and Performance Measurement." Journal of Political Economy, 100: 598-614.

Baker, W. E., R. R. Faulkner, and G. A. Fisher.

1988 "Hazards of the Market: The Continuity and Dissolution of Interorganizational Market Relationships." American Sociological Review, 63: 147-177.

Baker, G., Gibbons, R., and K. J. Murphy.

2002 "Relational Contracts and the Theory of the Firm." Quarterly Journal of Economics, 117: $39-84$.

Barley. S. R.

1996 "Technicians in the Workplace: Ethnographic Evidence for Bringing Work into Organization Studies." Administrative Science Quarterly, 37: 262-281.

Baron, J. N., and J. Pfeffer.

1994 "The Social Psychology of Organizations and Inequality." Social Psychology Quarterly, 57: 190-209.

Baron, J. N.

1984 "Organizational Perspectives on Stratification." Annual Review of Sociology, 10: 37-69. 
Bates, R. H., Greif, A., Levi, M., Rosenthal, J. L., and B. Weingast. 2000 "Analytic Narratives Revisited ." Social Science History, 24: 685-696.

Bendor, J., and P. Swistak.

1997 "The Evolution of Norms." American Journal of Sociology, 106: 1493-1545.

Bensaou, M.

1999 "Portfolio of Buyer-Supplier Relationships." Sloan Management Review, 40: 35-44.

Blau, P.

1955 The Dynamics of Bureaucracy. Chicago: University of Chicago Press.

Bradach, J. L., and R. G. Eccles.

1989 "Price, Authority, and Trust: From Ideal Types to Plural Forms." Annual Review of Sociology, 15: $97-118$.

Broschak, J. P.

2002 "Do the Actors Make the Play? Individual Mobility and the Dissolution of Market Ties." Working Paper, University of Illinois.

Cappelli, P.

1999 "Career Jobs Are Dead." California Management Review, 42: 146-167.

Clark, K. B., and S. C. Wheelwright.

1992 "Organizing and Leading 'Heavyweight' Development Teams." California Management Review, 34: 9-28.

Dalton, M.

1959 Men Who Manage. New York: John Wiley \& Sons.

Department of Health and Human Services.

1997 "Good Clinical Practice: Consolidated Guideline." Federal Register, 62: 25692-25709.

Doeringer, P. B., and M. J. Piore.

1971 Internal Labor Markets and Manpower Analysis. Lexington: Heath.

Dyer, J. H., and H. Singh.

1998 "The Relational View: Cooperative Strategy and Sources of Interorganizational Competitive Advantage." Academy of Management Review, 23: 660-679.

Dyer, J. H.

1996 "How Chrysler Created an American Keiretsu." Harvard Business Review: 32-46.

Eccles, R. G., and H. C. White.

2088 "Price and Authority in Inter-Profit Center Transactions." American Journal of Sociology, 94: S17-S51. 
Ellison, G., and E. Glaeser.

1997 "Geographic Concentration in U.S. Manufacturing Industries: A Dartboard Approach." Journal of Political Economy, 105: 889-927.

Eisenhardt, K. M.

1989 "Building Theories from Case Study Research." Academy of Management Review, 14: 532550.

Florida, R., and M. Kenney.

1991 "Transplanted Organizations: The Transfer of Japanese Industrial Organization to the U.S." American Sociological Review, 56: 381-398.

Gant, J., Ichniowski, C. and K. Shaw.

2002 "Social Capital and Organizational Change in High-involvement and Traditional Work Organizations." Journal of Economics and Management Strategy, 11: 289-328.

Glaeser, B. G., and A. Straus.

1967 The Discovery of Grounded Theory: Strategies for Qualitative Research. New York: Aldine de Gruyter.

Gouldner, A.

1954 Patterns of Industrial Bureaucracy. New York: The Free Press.

Granovetter, M.

1985 "Economic Action and Social Structure: The Problem of Embeddedness." American Journal of Sociology, 91: 481-510.

1992 "Problems of Explanation in Economic Sociology," in N. Nohria, and R. G. Eccles (eds.), Networks and Organizations: Structure, Forms, and Action. Boston: Harvard Business School Press, 25-56.

Greif, A.

1998 "Historical and Comparative Institutional Analysis." American Economic Review, 88: 80-84.

Gulati, R., and M. Gargiulo.

1999 "Where Do Interorganizational Networks Come From?" American Journal of Sociology, 104: 1439-1493.

Heide, J. B., and A. S. Miner.

1992 "The Shadow of the Future: Effects of Anticipated Interaction and Frequency of Contact on Buyer-Seller Cooperation." Academy of Management Journal, 35: 265-291.

\section{Helper, S. and M. Sako.}

2000 "Supplier Relations in Japan and the United States: Are They Converging?" Sloan Management Review, 36: 77-84. 
Helper, S., Macduffie, J. P., and C. Sabel.

2000 "Pragmatic Collaborations: Advancing Knowledge While Controlling Opportunism." Industrial and Corporate Change, 9: 443-488.

Holmström, B., and P. Milgrom.

1991 "Multitask Principal-Agent Analyses: Incentive Contracts, Asset Ownership, and Job Design." Journal of Law, Economics, and Organization, 7: 24-52.

Ingram, P., and P. W. Roberts.

2000 "Friendships Among Competitors in the Sidney Hotel Industry." American Journal of Sociology, 106: 387-423.

Ingram, P., and E. Lifschitz.

2000 "Community in Industry: Inter-builder Ties and Organizational Failure in Clyde River Shipbuilding, 1711-1990." Working Paper, Columbia University.

Itoh, $\mathbf{H}$.

1994 "Coordination, Specialization, and Incentives in Product Development Organization." In M.

Aoki and R. Dore (eds.), The Japanese Firm: Sources of Competitive Strength: 265-284. New York: Oxford University Press.

Jacoby, S. M.

1999 "Premature Reports of Demise." California Management Review, 42: 168-179.

Kalleberg, A. L.

2001 "The Advent of the Flexible Workplace." In D. B. Cornfield, K. E. Campbell and H. J. McCammon (eds.), Working in Restructured Workplaces: 437-453. Thousand Oaks, CA: Sage Publications.

Kandori, M.

1992 "Social Norms and Community Enforcement." Review of Economic Studies, 59: 63-80.

Kerr, S.

1975 "On the Folly of Rewarding A, While Hoping for B." Academy of Management Journal, 18: 769-783.

Kunda, G., Barley, S. R., and J. Evans.

2002 "Why Do Contractors Contract? The Experience of Highly Skilled Technical Professionals in a Contingent Labor Market." Industrial \& Labor Relations Review, 55: 234-261.

Lazear, E. P.

1989 "Pay Equality and Industrial Politics." Journal of Political Economy, 97: 561-580.

Mathieu, M.

1997 New Drug Development: A Regulatory Overview. Waltham, MA: Parexel International Corp. 
2003 Pharmaceutical R\&D Statistical Sourcebook. Waltham, MA: Parexel International Corp.

McMillan, J., and C. Woodruff.

1999 "Interfirm Relationships and Informal Credit in Vietnam." Quarterly Journal of Economics, 114: $1285-1320$.

Meyer, J., and B. Rowan.

1977 "Institutional Organizations: Formal Structure as Myth and Ceremony." American Journal of Sociology, 83: 340-363.

Miles, M. B., and A. M. Huberman.

1994 Qualitative Data Analysis. Thousand Oaks: Sage Publications.

Neumark, D.

2000 On the Job: Is Long-term Employment a Thing of the Past? New York: Russel Sage Foundation.

Osterman, $\mathbf{P}$.

1994 "How Frequent is Workplace Transformation and Who Adopts It?" Industrial and Labor Relations Review, 47: 173-188.

Pil, F. K., and J. P. Macduffie.

1996 "The Adoption of High-involvement Work Practices." Industrial Relations, 35: 423-455.

Podolny, J. and Page, K. L.

1998 "Network Forms of Organization." Annual Review of Sociology, 24: 57-76.

Powell, W. W.

1987 "Hybrid Organizational Arrangements: New Form or Transitional Development?" California Management Review, 30: 67-87.

1990 "Neither Market nor Hierarchy: Network Forms of Organizations." Research in Organizational Behavior, 12: 295-336.

2001 "The Capitalist Firm in the Twenty-First Century: Emerging Patterns in Western Enterprise." In P. DiMaggio (ed.), The Twenty-First Century Firm: 33-68. Princeton: Princeton University Press.

Powell, Walter W., Koput, Kenneth W., and Laurel Smith-Doerr.

1996 "Interorganizational Collaboration and the Locus of Innovation: Networks of Learning in Biotechnology." Administrative Science Quarterly, 41: 116-145.

Raub, W., and J. Weesie.

1990 "Reputation and Efficiency in Social Interactions: An Example of Network Effects." American Journal of Sociology, 96: 626-654.

Rousseau, D. M.

1995 Psychological Contracts in Organizations. Thousand Oaks: Sage. 


\section{Spilker, B.}

1991 Guide to Clinical Trials. New York: Raven Press.

\section{Stinchcombe, A.}

1990 Information and Organizations. Berkeley: University of California University Press.

\section{Uzzi, B.}

1996 "The Sources and Consequences of Embeddedness for the Economic Performance of Organizations: The Network Effect." American Sociological Review, 61: 674-698.

1997 "Social Structure and Competition in Interfirm Networks: The Paradox of Embeddedness." Administrative Science Quarterly, 42: 35-67.

Vallas, S. P.

2003 "Why Teamwork Fails: Obstacles to Workplace Change in Four Manufacturing Plants." American Sociological Review, 68: 223-250.

\section{von Hippel, E.}

1998 "Economics of Product Development by Users: The Impact of 'Sticky' Local Information." Management Science, 44: 629-644.

Williamson, O. E.

1975 Markets and Hierarchies. New York: The Free Press.

1985 The Economic Institutions of Capitalism. New York: The Free Press.

1996 The Mechanisms of Governance. New York: The Free Press.

Zaheer, A., McEvily, B., and V. Perrone. 1998 "Does Trust Matter? Exploring the Effects of Interorganizational and Interpersonal Trust on Performance." Organization Science, 9: 141-159.

Zhou, X., Zhao, W., Li, Q., and H. Cai.

2003 "Embeddedness and Contractual Relationships: Explorations in China's Transitional Economy." American Sociological Review, 68: 75-102.

\section{Zuboff, S.}

1988 In The Age of the Smart Machine. New York: Basic Books. 


\section{Tables and Figures}

Figure 1: Typical Organization of the Clinical Trials Process ${ }^{*}$

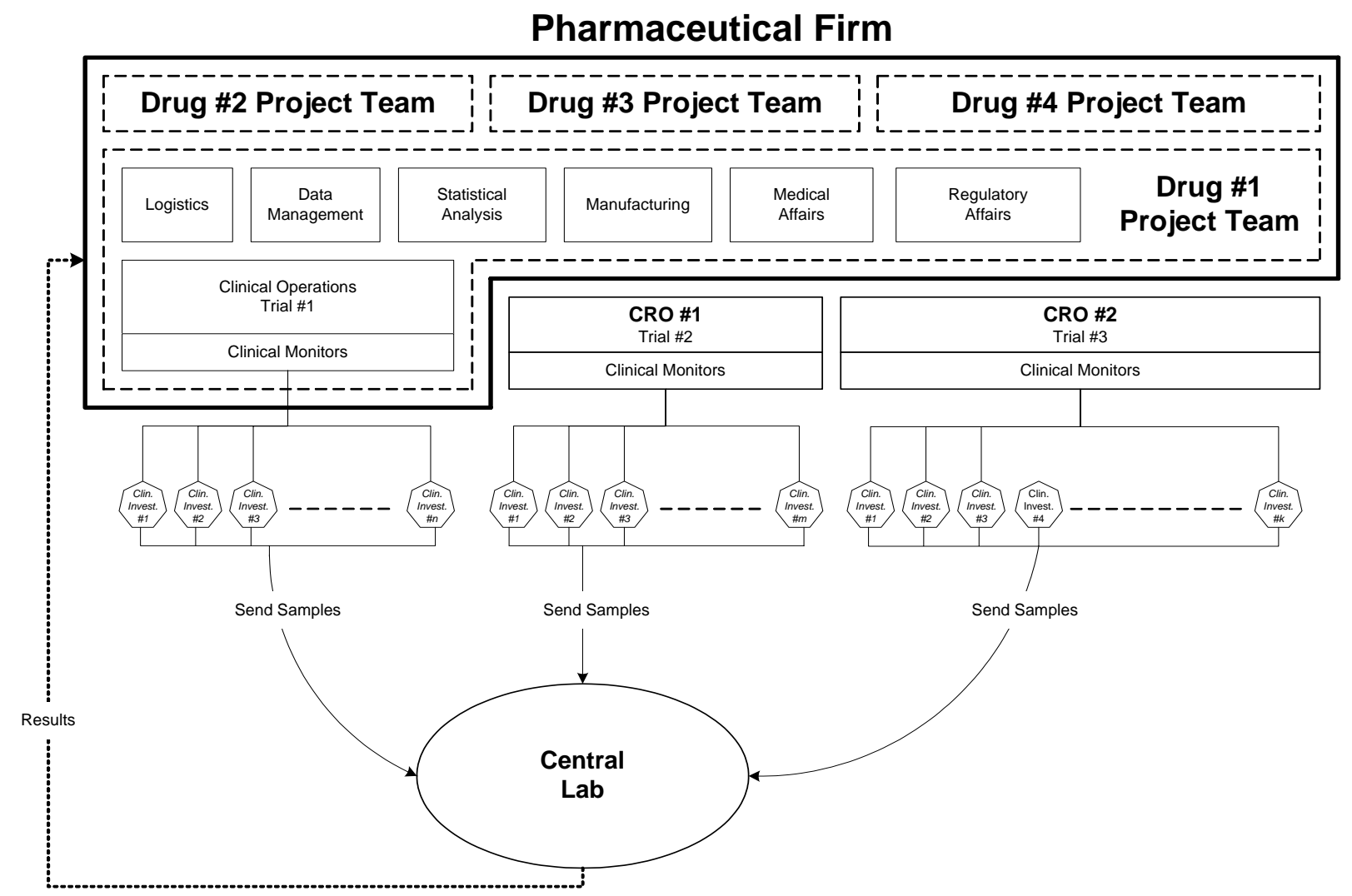

\footnotetext{
* The schema depicts typical organizational arrangements in clinical development. A pharmaceutical firm (whose boundary is drawn using the thick solid line) is concurrently developing three drugs, using three distinct cross-functional product teams (whose boundaries are drawn using the thin dotted line). The box corresponding to team \#1 has been blown up, revealing the different functions necessary to the successful development of drug \#1. For each drug, there is a portfolio of trials (three in the case of drug \#1, two of which - trial \#2 and trial \#3 — are outsourced to two different CROs). The clinical monitors (both inside the pharmaceutical firm and the CROs) oversee the gathering of clinical data that takes place in a variety of clinical sites (hospitals, private clinics, Academic Medical Centers) under the stewardship of clinical investigators. These clinical investigators send patient samples to a central laboratory, which processes them and sends back the results to the project team.
} 


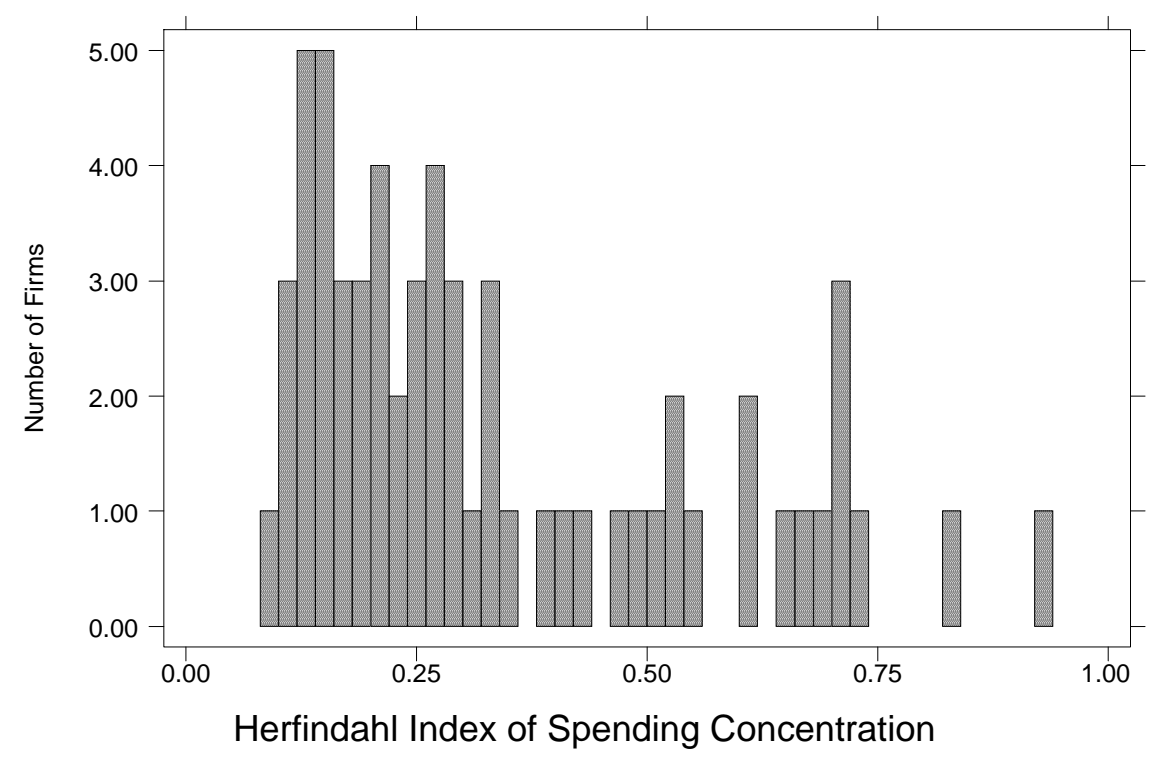

Figure 3: Adjusted Herfindahl Index of Spending Concentration ${ }^{* *}$

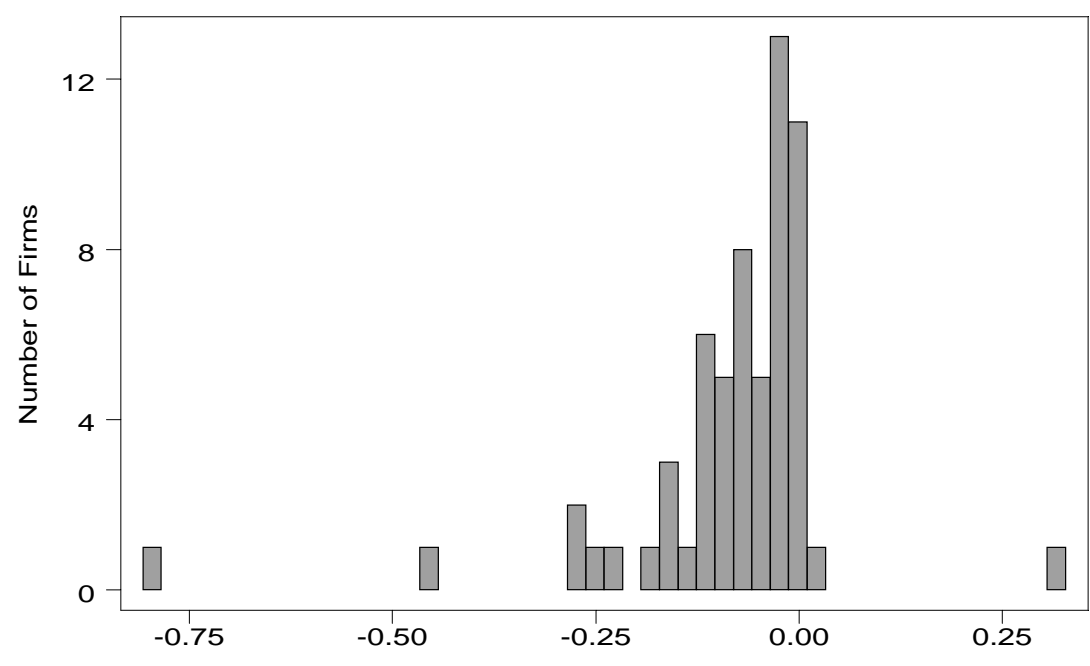

Herfindahl Index of Spending Concentration (adjusted for "small $n$ ")

\footnotetext{
** The calculations draw on a dataset of 1,423 CRO contracts from 61 large pharmaceutical and biotechnology companies. Twice a year since 1991, FastTrack, Inc. has gathered data from subscribing companies. Like Uzzi (1996), the data provide good information at the "buyer-supplier match" level of analysis.
} 
Figure 4: The Relational Architecture of Governance in Clinical Development Outsourcing

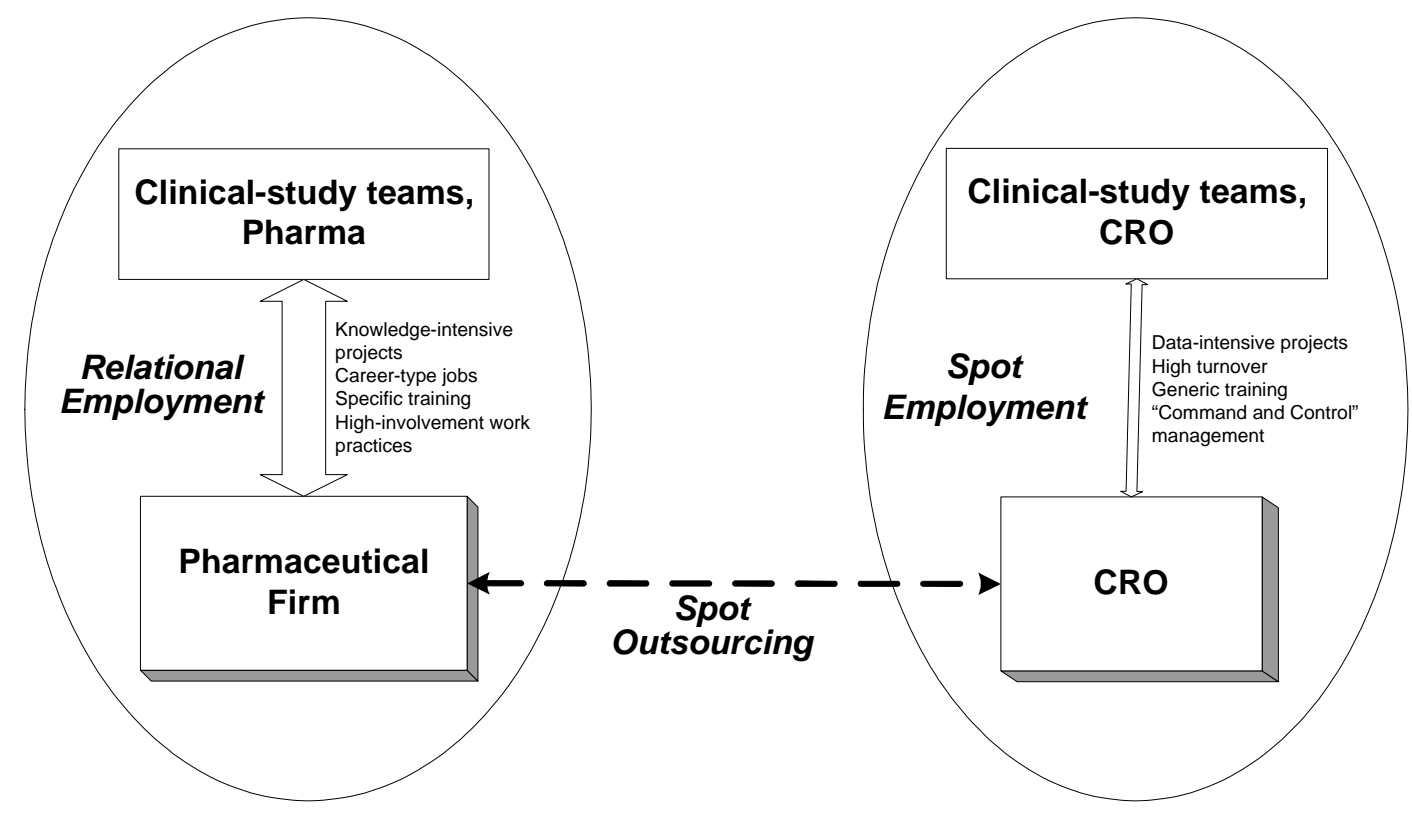

Figure 5: The Relational Architecture of Governance in Lab-services Outsourcing

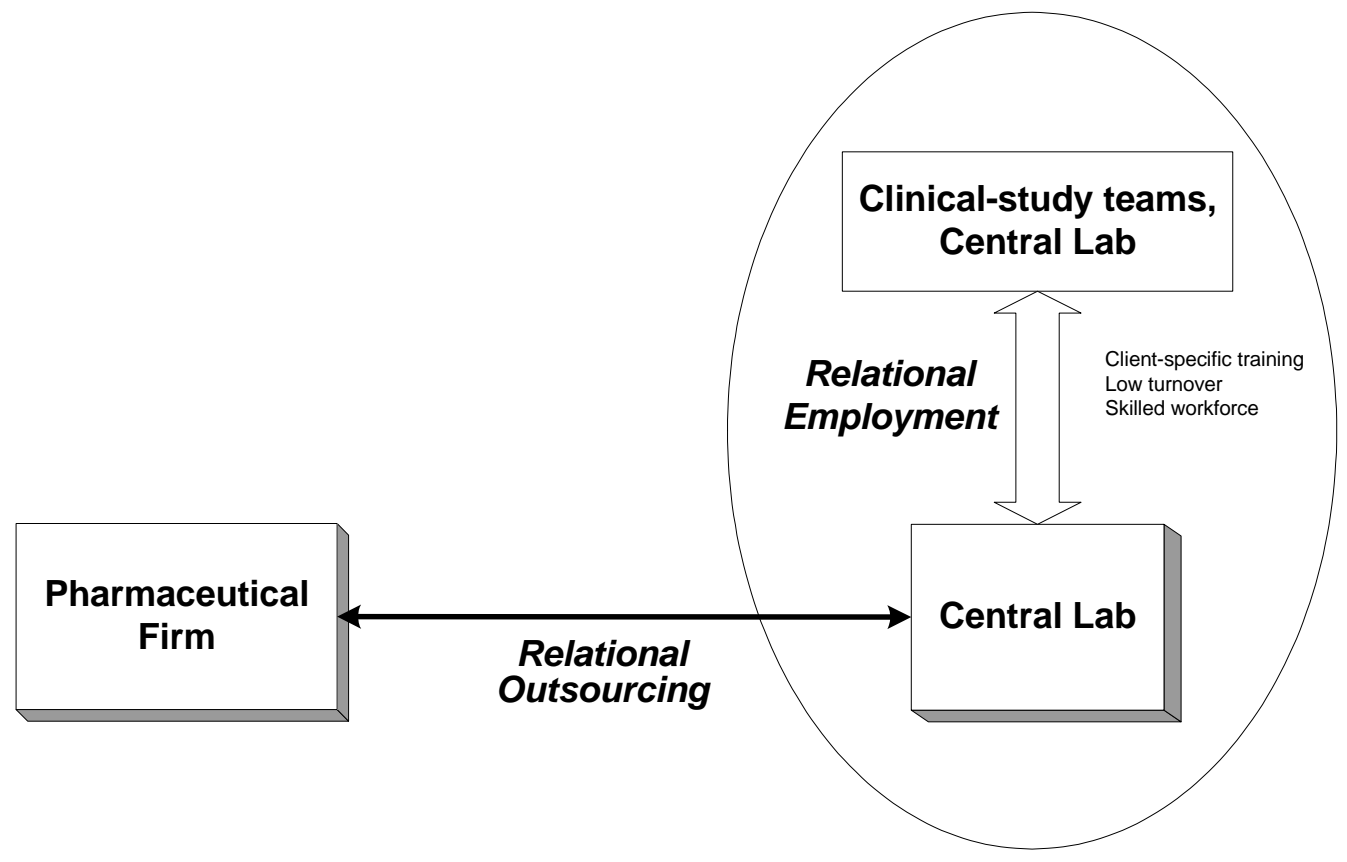


Table 1: Characteristics of the firms in the sample

\begin{tabular}{|c|c|c|c|c|c|c|c|}
\hline $\begin{array}{l}\text { Type of } \\
\text { firm }\end{array}$ & $\begin{array}{c}\text { Number of } \\
\text { drugs on the } \\
\text { market } \\
(2000)\end{array}$ & Location & $\begin{array}{c}\text { Year } \\
\text { outsourcing } \\
\text { began }\end{array}$ & $\begin{array}{c}\text { Number } \\
\text { of CROs } \\
(2000)\end{array}$ & $\begin{array}{c}\text { Number } \\
\text { of Central } \\
\text { Labs } \\
(2000)\end{array}$ & $\begin{array}{l}\text { Number of } \\
\text { interviews }\end{array}$ & $\begin{array}{c}\text { Number of } \\
\text { interview } \\
\text { hours }\end{array}$ \\
\hline Large & 6 & Midwest & 1993 & 13 & n.a. & 14 & 16 \\
\hline Large & 16 & East Coast & 1994 & 29 & 2 & 7 & 6.5 \\
\hline Large & 3 & $\begin{array}{l}\text { Southern } \\
\text { California }\end{array}$ & 1985 & 10 & 2 & 25 & 34 \\
\hline Medium & 8 & $\begin{array}{l}\text { Northern } \\
\text { California }\end{array}$ & 1990 & 20 & 4 & 6 & 10 \\
\hline Medium & 6 & $\begin{array}{l}\text { Northern } \\
\text { California }\end{array}$ & 1992 & 12 & 2 & 10 & 11 \\
\hline Small & 0 & $\begin{array}{c}\text { Pacific } \\
\text { Northwest }\end{array}$ & 1995 & 4 & 1 & 20 & 18 \\
\hline
\end{tabular}

Size in sales: small $=\$ 0-100$ million; medium $=\$ 100-3,000$ million; large $=\$ 3-50$ billion.

Table 2: Summary of cross-site ethnographic evidence for impediments to embedded supply relationships in six pharmaceutical and biotech firms

\section{CROs Central Labs}

Employees are "data mules"

There are benefits to "Partnerships"

Outsourcing is purely tactical (i.e., we only have arms-length ties)

There are learning curves (i.e., specific human capital is important)

Outsourcing in an insurance policy for our own employees

We need to constantly monitoring the suppliers and their employees

We may lose the soft data

We outsource selectively

Teams have a lot of turnover

You are as good as your last project (i.e., no generalized reputations)

We got burned with "Preferred Provider Agreements"

If resources were not an issue, we would not outsource

\footnotetext{
Numbers in cells represent frequency of responses by interviewees aggregated across person-cases. Empty cells indicate that no responses were made by interviewees in that category.
} 


\section{Appendix: Open-ended Interview Items}

The items listed below do not constitute an exhaustive list of the questions asked during the ethnographic fieldwork, but provide a sense of how the statements reported in the text were elicited.

\section{Internal Organization}

Tell me what's involved with monitoring. Have you done it for other companies than [Firm X]?

How are clinical monitors recruited and trained? How are monitors evaluated? How is their job performance tracked?

Is monitor turnover an issue for your firm? Is this turnover internal (i.e. promotion), or external? How much therapeutic specialization is there for monitors?

What kind of incentives do you provide to monitors? What are possible promotion paths for in-house monitors?

How many monitors are working here? Are they permanent employees? Are there also temps, or contract monitors?

How is project management organized? Who are the project managers? What are their background?

\section{$\underline{\text { Interfirm Contracts }}$}

Why do you outsource?

Is there a firm-wide outsourcing policy or is the decision taken on a project-specific basis?

Who owns the data? Who owns the molecule?

How did outsourcing start in your company? How long ago? What was the initial event that triggered adoption of outsourcing?

What services exactly are being outsourced? How are CROs/Central Labs selected?

How important is therapeutic expertise? How are contracts drafted? How has it changed over time?

Are the incentives built in the contracts for speed, quality, or both?

Could you walk me through the financial negotiation with a CRO/Central Lab? Is price the most

determinant characteristic of a bid? How many bids are received on average?

When you deal with a $\mathrm{CRO} /$ Central Lab repeatedly and are happy about their performance, do you expect them to give you a lower price?

\section{$\underline{\text { Buyer-Supplier Interactions }}$}

How many CROs/Central Labs is your company dealing with?

How frequent is repeat business with CROs? With Central Labs? Why?

Do you ever hang out with your counterparts at the CRO/Central Lab after work?

How are CROs/Central Labs monitored and evaluated?

How does one deal with changes and renegotiation as the trial proceeds?

Who makes the determination of whether the CRO or [Firm X] must pay for scope changes?

\section{Relationship Outcomes}

Do you have Preferred Provider Agreements? How easy/hard is it to have long-term "hand-in-glove" relationships with CROs/Central Labs? Why? What are the benefits of such relationships? What are the drawbacks?

Do CROs/Central Labs have reputations? How do you learn about the quality of different CROs? 